Article

\title{
Impact of a Nosocomial COVID-19 Outbreak on a Non-COVID-19 Nephrology Ward during the First Wave of the Pandemic in Spain
}

\author{
María Milagro Montero ${ }^{1} * \mathbb{D}$, Carlota Hidalgo López ${ }^{2}$, Inmaculada López Montesinos ${ }^{1}$, Luisa Sorli ${ }^{1}$, \\ Cristina Barrufet Gonzalez ${ }^{2}$, Judith Villar-García ${ }^{1}$, Roberto Güerri-Fernández ${ }^{1}$, Milagros Herranz ${ }^{2}$, \\ Marta Crespo ${ }^{3}$, María Dolores Arenas Jiménez ${ }^{3}$, Julio Pascual ${ }^{3}$, Cristina González Juanes ${ }^{2}$ and \\ Juan P. Horcajada ${ }^{1, *}$
}

check for updates

Citation: Montero, M.M.; Hidalgo

López, C.; López Montesinos, I.; Sorli, L.; Barrufet Gonzalez, C.;

Villar-García, J.; Güerri-Fernández, R.; Herranz, M.; Crespo, M.; Arenas Jiménez, M.D.; et al. Impact of a Nosocomial COVID-19 Outbreak on a Non-COVID-19 Nephrology Ward during the First Wave of the Pandemic in Spain. Antibiotics 2021, 10, 619. https://doi.org/10.3390/ antibiotics10060619

Academic Editor: Maria Bagattini

Received: 12 April 2021

Accepted: 20 May 2021

Published: 22 May 2021

Publisher's Note: MDPI stays neutral with regard to jurisdictional claims in published maps and institutional affiliations.

Copyright: (C) 2021 by the authors Licensee MDPI, Basel, Switzerland. This article is an open access article distributed under the terms and conditions of the Creative Commons Attribution (CC BY) license (https:// creativecommons.org/licenses/by/ $4.0 /)$.
1 Infectious Diseases Service, Hospital del Mar, Institut Hospital del Mar d'Investigacions Mèdiques (IMIM), Universitat Autònoma de Barcelona (UAB), CEXS-Universitat Pompeu Fabra, 08003 Barcelona, Spain; ilopezmontesinos@parcdesalutmar.cat (I.L.M.); lsorli@parcdesalutmar.cat (L.S.); jvillar@parcdesalutmar.cat (J.V.-G.); rguerri@parcdesalutmar.cat (R.G.-F.)

2 Health Services Evaluation and Clinical Epidemiology Department, Institut Hospital del Mar d'Investigacions Mèdiques (IMIM), Hospital del Mar, 08003 Barcelona, Spain; chidalgo@parcdesalutmar.cat (C.H.L.); cbarrufet@parcdesalutmar.cat (C.B.G.); mherranz@parcdesalutmar.cat (M.H.); cgonzalez@parcdesalutmar.cat (C.G.J.)

3 Department of Nephrology, Hospital del Mar, 08003 Barcelona, Spain; mcrespo@parcdesalutmar.cat (M.C.); marenasjimenez@parcdesalutmar.cat (M.D.A.J.); jpascual@parcdesalutmar.cat (J.P.)

* Correspondence: mmontero@psmar.cat (M.M.M); jhorcajada@psmar.cat (J.P.C.); Tel.: +34-93-248-3251 (M.M.M.)

Abstract: Introduction: The aim of this study was to analyze a nosocomial coronavirus disease 2019 (COVID-19) outbreak that occurred on a polyvalent non-COVID-19 ward at a tertiary care university hospital in Spain during the first wave of the pandemic and to describe the containment measures taken. The outbreak affected healthcare workers (HCWs) and kidney disease patients including transplant patients and those requiring maintenance hemodialysis. Methods: The outbreak investigation and report were conducted in accordance with the Orion statement guidelines. Results: In this study, 15 cases of COVID-19 affecting 10 patients and 5 HCWs were identified on a ward with 31 beds and $43 \mathrm{HCWs}$. The patients had tested negative for severe acute respiratory syndrome coronavirus 2 infection on admission. One of the HCWs was identified as the probable index case. Five patients died (mortality rate, 50\%). They were all elderly and had significant comorbidities. The infection control measures taken included the transfer of infected patients to COVID-19 isolation wards, implementation of universal preventive measures, weekly PCR testing of patients and HCWs linked to the ward, training of HCWs on infection control and prevention measures, and enhancement of cleaning and disinfection. The outbreak was contained in 2 weeks, and no new cases occurred. Conclusion: Nosocomial COVID-19 outbreaks can have high attack rates involving both patients and HCWs and carry a high risk of patient mortality. Hospitals need to implement effective infection prevention and control strategies to prevent nosocomial COVID-19 spread.

Keywords: nosocomial outbreak; COVID-19; infection control

\section{Introduction}

Coronavirus disease 19 (COVID-19), caused by severe acute respiratory syndrome coronavirus 2 (SARS-CoV-2), was first identified in Wuhan, China, in December 2019 and subsequently spread to 188 countries around the world [1]. Since 31 December 2019 and as of April 2021, 147,443,848 cases of COVID-19 and 3,117,542 deaths have been reported. A substantial number of the cases-49,599,293 - correspond to Europe [2].

According to recent data from the Catalan Health Department, there were 633,227 COVID-19 cases and 21,895 deaths in Catalonia as of 5 May 2021 [3]. The cumulative 
number of cases at our hospital was 3194 and 900 of these had occurred during the first week of April 2020.

COVID-19 is a threat in hospital settings since it can cause large outbreaks among healthcare workers (HCWs) [4] and patients, clearly posing unique infection prevention and control (IPC) challenges [5].

Several outbreaks were initially reported in Wuhan, including one at a university hospital with 138 cases, $41 \%$ of which were suspected to be nosocomial (17 patients and 40 HCWs) [6-8]. According to a recent report, one in five confirmed cases of COVID-19 in the United States involves an HCW [9].

There is sufficient evidence to support the hypothesis that SARS-CoV-2 is transmitted primarily by droplets that remain airborne following aerosol-generating procedures [10-12]. The disease can also be transmitted by asymptomatic or presymptomatic individuals [13-15]. Since hospitals are often epicenters of newly circulating infections, HCWs are at risk, both at work and in the community $[7,16]$.

Enhancement of IPC measures, such as the creation of separate COVID-19 and nonCOVID-19 areas, is essential for reducing hospital outbreaks [17,18]. During the first wave of the pandemic, a large part of our hospital was converted into a COVID-19 facility. This process involved major structural and organizational changes and created difficulties in the management of COVID-19-free areas.

Patients with kidney disease, both those requiring maintenance hemodialysis and transplant recipients, are at high risk for COVID-19 and a poor outcome. Preventive measures, thus, are crucial $[19,20]$.

In this article, we report on a nosocomial COVID-19 outbreak that affected HCWs and patients on a nephrology ward at a tertiary care university hospital in Spain and describe the infection control measures implemented. The outbreak was associated with a high attack rate and high patient mortality.

\section{Materials and Methods}

In preparing this report, we followed the ORION statement guidelines for transparent reporting of outbreak reports and intervention studies of nosocomial infection [21].

\subsection{Institutional Setting and Study Period}

This study was conducted at Hospital del Mar in Barcelona, Spain from 6 April to 30 May 2020. Hospital de Mar is a tertiary care hospital with 413 beds and 16 hospitalization units; it has 4545 HCWs, including 929 physicians and residents, 1332 nurses, and 997 care assistants.

All patients admitted to the hospital during the study period were screened per protocol for COVID-19 using reverse transcriptase-polymerase chain reaction (PCR). Depending on the result, they were assigned to a COVID-19 or a non-COVID-19 ward. HCWs were not routinely tested during this period unless they had compatible clinical symptoms. Access to the hospital was exclusively restricted to HCWs. Family visits were forbidden.

The COVID-19 outbreak occurred on a polyvalent hospitalization ward that provides care to general surgery, nephrology, and kidney transplant patients.

\subsection{Study Objectives}

The aim of this study was to describe a nosocomial COVID-19 outbreak in a polyvalent non-COVID-19 hospital unit and to report on the measures taken to detect and control the outbreak.

\subsection{Variables and Data Sources}

Demographic, clinical, laboratory, and epidemiological data were collected from hospital and primary care electronic medical records and included the following: age, sex, presence, and severity of comorbidities assessed using the Charlson comorbidity index [22], days from exposure to positive PCR test for COVID-19, clinical symptoms, chest X-ray 
findings, treatment of COVID-19, and outcomes. Individuals were followed until death or for at least 30 days from the first positive test.

\subsection{Clinical Classification of COVID-19 and Definition of Case}

Individuals were recorded as cases if at least one of the following tests was interpreted as positive for SARS-CoV-2: PCR or rapid diagnostic test based on antigen detection in a sample taken from the respiratory tract (throat swab, sputum, endotracheal aspirate, or bronchoalveolar lavage fluid). Contacts were identified based on potential exposure to a probable index case within $48 \mathrm{~h}$ of symptom onset. Close contact was defined as being within 6 feet of an infected person for 15 consecutive minutes or more.

For the purpose of the investigation, cases were classified as probably hospitalacquired if the patient developed COVID-19 symptoms (or had their first positive PCR test) between day 8 and 14 of admission and as definitely hospital-acquired if they developed symptoms or tested positive later.

On detection of the outbreak, patients and HCWs were interviewed daily over a period of 14 days to check for typical COVID-19-symptoms. Universal PCR testing was also performed among all patients on the affected ward and all HCWs linked to the ward to detect asymptomatic cases.

\subsection{Intervention Methods}

The following measures were taken to evaluate the hospital's strategy for the early detection and containment of potential COVID-19 outbreaks:

- Review of medical files, laboratory records, and radiographic findings of confirmed cases;

- $\quad$ Review of inpatient electronic tracking system to determine the movement of cases within and between units and to identify the exact location of beds occupied;

- $\quad$ Scrutiny of staff records to understand work areas and shift patterns of infected staff;

- $\quad$ Personal and telephone interviews with HCWs involved in the care of affected patients and preparation of a contact list for PCR studies;

- $\quad$ Closure of affected ward with no admission for the first 2 weeks of the outbreak;

- Banning of transfers to other wards;

- Weekly PCR testing of all patients and HCWs (including cleaning staff) in the affected ward;

- $\quad$ Mandatory confinement for HCWs with a positive PCR or who were close contacts with positive cases as per the hospital protocol;

- $\quad$ Transfer of patients with a positive PCR to COVID-19 isolation wards;

- Daily safety meeting with all staff involved in the outbreak;

- Detailed analyses of human behaviors and interactions, room sizes, and ventilation characteristics of the ward and common areas.

\subsection{Statistical Analysis}

Continuous quantitative variables are presented as the median and interquartile range (IQR). Continuous variables were compared using the $t$ test or Mann-Whitney $U$ test and categorical variables using the Fisher's exact test or Pearson's $\chi^{2}$ test, as appropriate. Analysis of variance was used to determine if the means of groups were significantly different from each other. All $p$-values were two tailed, and statistical significance was set at $<0.05$. Statistical analyses were performed in SPSS V. 21.0 (SPSS Inc., Chicago, IL, USA).

\section{Results}

\subsection{Epidemiological Curve}

Over an 8-week study period (6 April to 31 May), there were 15 confirmed COVID-19 cases: 10 in patients and 5 in HCWs. The epidemiological curve is shown in Figure 1. 


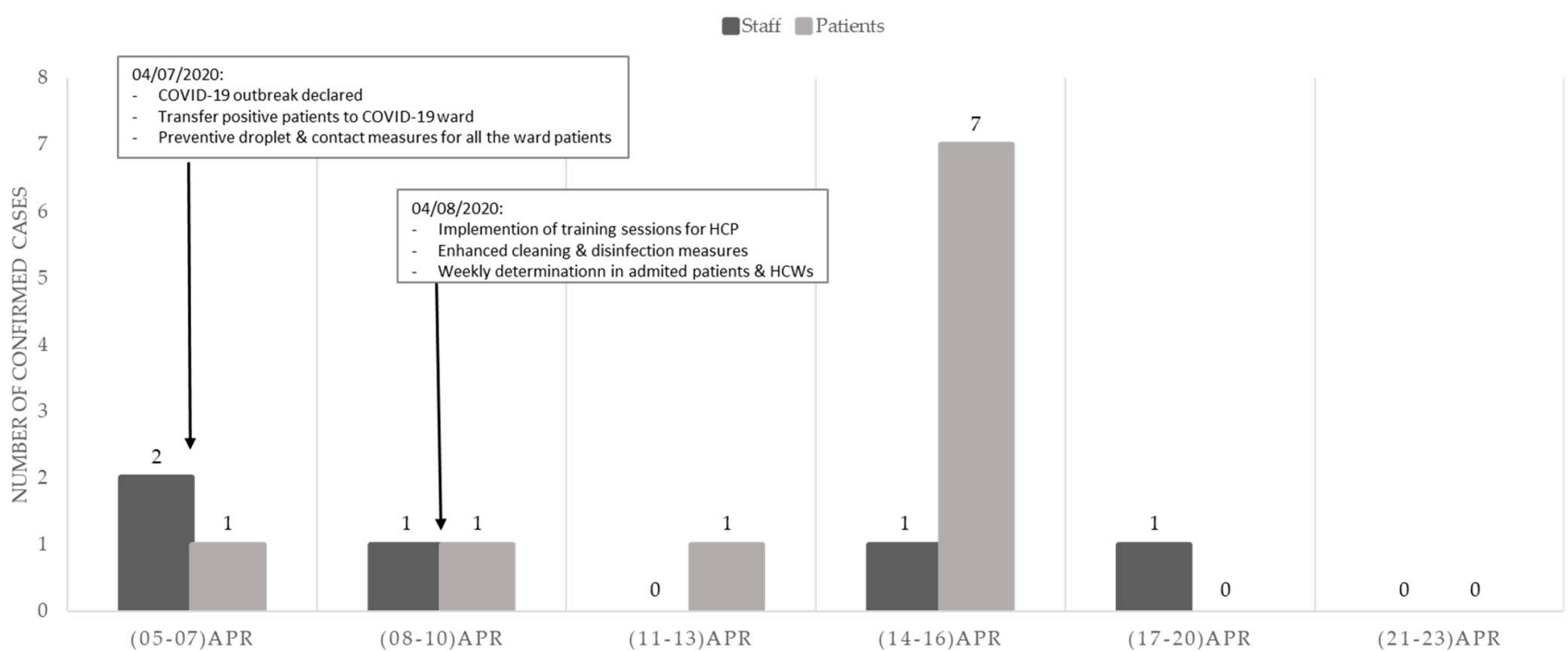

Figure 1. Epidemiological curve: COVID-19 coronavirus disease 2019; HCW healthcare workers; ICP infection control and prevention.

\subsection{Case Detection and Epidemiological Investigation}

The outbreak was declared on 7 April 2020. Based on the date of the positive PCR test, one of the infected HCWs was identified as the probable index case and was assumed to have acquired the infection in the community. After this date, a cluster of patients and HCWs from the same unit, all symptomatic, tested positive for COVID-19 by PCR. The distribution of all individuals is shown in Table 1 and Figure 2. The polyvalent ward consisted of 16 rooms and 32 beds (there were no private rooms).

Table 1. Clinical and demographic characteristics of patients and healthcare workers with COVID-19 by disease severity and survival.

\begin{tabular}{|c|c|c|}
\hline & $\begin{array}{c}\text { SARS-CoV-2-Positive } \\
\text { Hospitalized Patients }(n=10 / 31)\end{array}$ & $\begin{array}{l}\text { SARS-CoV-2-Positive } \\
\text { Healthcare Workers }(n=5 / 43)\end{array}$ \\
\hline Age * years, mean $(\mathrm{SD})$ & $68.7(15.5)$ & $52(7.8)$ \\
\hline $\begin{array}{c}\text { Male } \\
\text { Female }\end{array}$ & $\begin{array}{c}\text { Sex } \\
5(50 \%) \\
5(50 \%)\end{array}$ & $5(100 \%)$ \\
\hline $\begin{array}{l}\text { Days from admission to positive PCR, } \\
\text { median (IQR) }\end{array}$ & $10.5(6-22)$ & \\
\hline $\begin{array}{l}\text { No comorbidities } \\
\text { Charlson Comorbidity Index } \geq 2\end{array}$ & $\begin{array}{c}\text { Underlying diseases } \\
2(20) \\
8(80)\end{array}$ & $\begin{array}{c}5(100 \%) \\
0\end{array}$ \\
\hline $\begin{array}{c}\text { Fever } \\
\text { Cough } \\
\text { Fatigue } \\
\text { Dyspnea } \\
\text { Diarrhea } \\
\text { Asymptomatic } \\
\text { Radiographic findings }\end{array}$ & $\begin{array}{c}\text { Clinical presentation } \\
\text { Symptoms } \\
7(70 \%) \\
5(50 \%) \\
8(80 \%) \\
7(70 \%) \\
2(20 \%) \\
2(20 \%) \\
7(70 \%) \\
\end{array}$ & $\begin{array}{c}5(100 \%) \\
3(60 \%) \\
3(60 \%) \\
0 \\
2(40 \%) \\
0 \\
0\end{array}$ \\
\hline $\begin{array}{l}\text { Died } \\
\text { Alive }\end{array}$ & $\begin{array}{c}\text { All-cause mortality } \\
5(50 \%) \\
5(50 \%)\end{array}$ & $5(100 \%)$ \\
\hline $\begin{array}{l}\text { No } \\
\text { Yes }\end{array}$ & $\begin{array}{c}\text { Mortality due to COVID-19 } \\
1(10 \%) \\
4(40 \%)\end{array}$ & $\begin{array}{l}- \\
-\end{array}$ \\
\hline
\end{tabular}

* Statistically significant difference. Data are presented as $n(\%)$ unless otherwise specified. SARS-CoV-2 severe acute respiratory syndrome coronavirus 2, COVID-19 coronavirus disease-19, SD standard deviation, IQR interquartile range. 


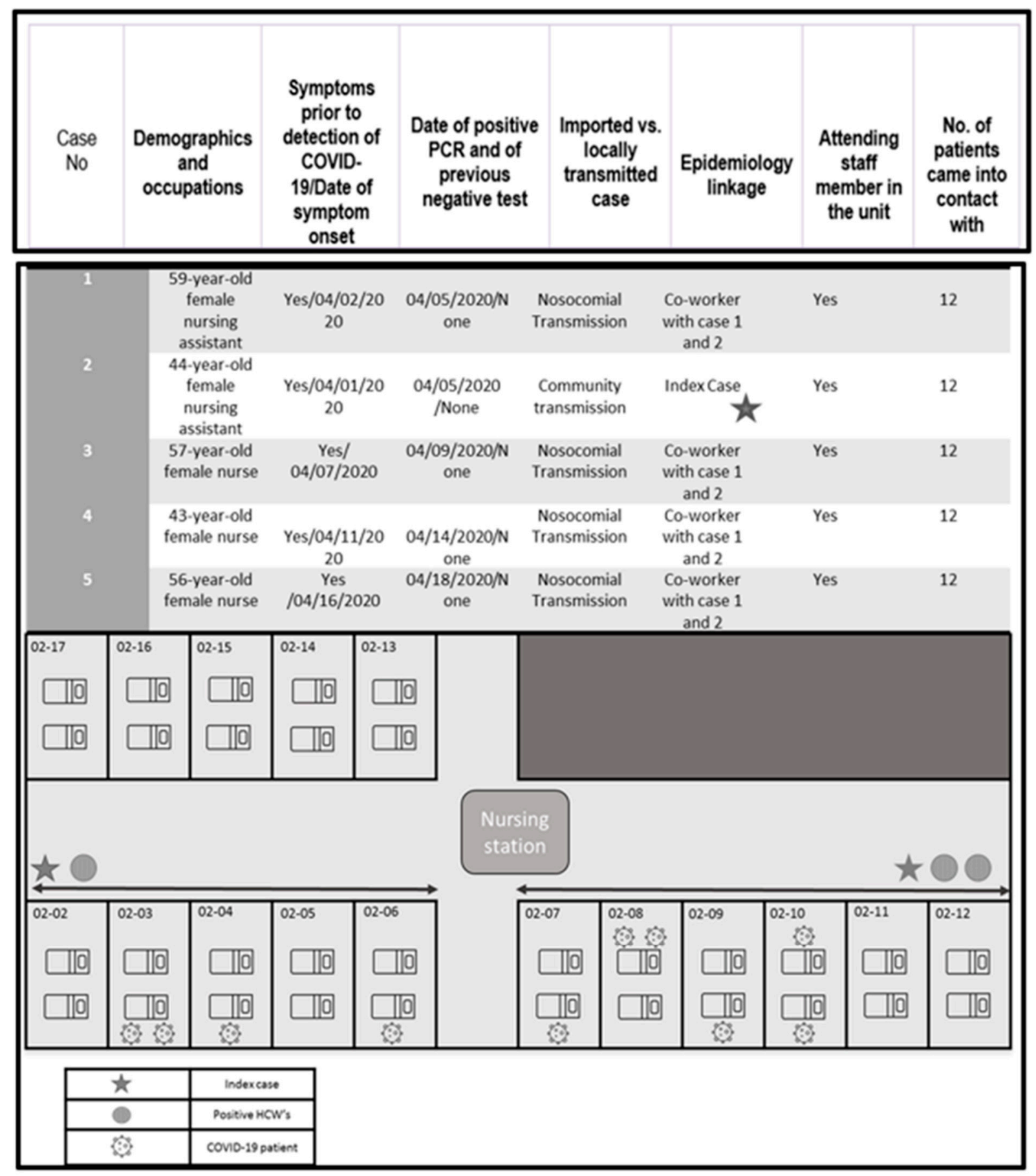

Figure 2. Distribution of HCWs and patients in the unit during the outbreak. Each nursing assistant and nurse had 12 patients under their care. The star shows the index case (nursing assistant). Additional information on the five HCWs with confirmed COVID-19 in the polyvalent ward is given in the box below the figure (demographic details, results of epidemiological investigation, and number of patients exposed).

The ward had a total staff of 43 HCWs (physicians, nurses, nursing and care staff, and cleaning staff) at the time of the outbreak. Of the 31 patients in the ward at this time, 10 patients, all in the nephrology section, tested positive for COVID-19. They had all been COVID-19-negative on admission. Five of the HCWs tested positive. The characteristics of the patients and HCWs are shown in Table 1. 


\subsection{Outbreak Management}

Once the outbreak had been identified, the following control measures were taken:

- Quarantine (14 days of preventive isolation for close-contact HCWs);

- Transfer of positive patients to COVID isolation ward;

- Implementation of preventive droplet and contact measures for all patients remaining in the ward, applicable to anyone entering the room: hand hygiene and use of surgical mask (or FFP2 mask for aerosol-generating procedures), eye protection (for aerosolgenerating procedures or procedures with a risk of splash), gown (and apron for splash protection), and gloves;

- $\quad$ Twice-weekly training sessions for all HCWs linked to the ward to emphasize the importance of preventing cross-infection and reinforce proper use of personal protection equipment (PPE) and hand hygiene. Before the COVID-19 pandemic, this ward had high compliance of infection control measures: great managing with isolation precautions, appropriate glove use, good hand hygiene compliance rate (2017: 87\%; 2018: 87\%; 2019: 69\%), and when the pandemic started, universal masking was carried out for all HCWs; unfortunately, the infection control program was not available full time for conducting observations in non-COVID-19 units during the first part of the pandemic - in order to that, we have no data of compliance rates for this time;

- Enhanced cleaning and disinfection: regular cleaning, followed by disinfection with $0.1 \%$ sodium hypochlorite (1000 ppm) of patient rooms (once a day), frequently touched surfaces, and all equipment in the affected ward (twice a day);

- Weekly PCR tests for patients and HCWs on the ward;

- Testing of proper operation of ventilation systems and adequate supplies of acceptablequality indoor air adapted to occupancy at any given time;

- These measures controlled the outbreak, and no new cases were detected up to the end of the study period (31 May).

\section{Discussion}

COVID-19 is primarily a community-spread disease with a risk of nosocomial transmission from visitors, HCWs, or patients who are incubating the infection, have a mild form of the disease, or are asymptomatic [14]. Hospital-based syndromic surveillance can facilitate the early detection of healthcare-associated outbreaks [23], and any surveillance system for HCWs must be supported by a comprehensive outbreak management strategy to achieve containment.

Response to outbreaks, however, is challenging due to the lack of research-based recommendations, particularly in the case of SARS-CoV-2, which is a novel pathogen that has spread rapidly throughout the world and caused community and hospital outbreaks [24].

Nosocomial infections have been documented in healthcare organizations that have strict contact and droplet precautions and use PPE designed to protect against droplet but not aerosol exposure.

We believe that the COVID-19 cases detected in the outbreak at our hospital might have been caused by airborne transmission of the virus from presymptomatic HCW carriers since family visits were forbidden during the study period. In other scenarios, hospitalacquired cases could result from asymptomatic infections or false-negative PCR results [25].

Of the $46 \mathrm{HCWs}$ in the study ward, $5(11 \%)$ tested positive for COVID-19, and they all had compatible clinical symptoms. Surveillance testing showed negative results for the remaining $41 \mathrm{HCWs.} \mathrm{In} \mathrm{other} \mathrm{words,} \mathrm{no} \mathrm{asymptomatic} \mathrm{carriers} \mathrm{were} \mathrm{identified.} \mathrm{Prompt}$ detection strategies such as routine PCR screening of HCWs, particularly in vulnerable areas, could help prevent disease spread.

Our outbreak illustrates how patients admitted to a COVID-19-free ward in a pandemic situation can become infected and possibly die. The mortality rate in our case was high, at 50\%. This is similar to rates reported elsewhere [26] and may be linked to the patients' advanced age and significant comorbidity (in our case, kidney disease). Nonetheless, in the observational COPE-Nosocomial Study, Carter et al. [27] concluded that nosocomial 
transmission was not associated with an increased risk of mortality and that it might even carry a lower risk than a community-acquired disease.

Our findings also provide further evidence that previous contact with healthcare facilities is common in patients who develop COVID-19 [19]. The actions taken by our hospital's infection control team in response to the outbreak limited the number of hospitalacquired cases to 10 and prevented the spread of the virus to other non-COVID wards, where it could have had a similar impact. Interestingly, the outbreak was controlled in a short period (2 weeks) [28].

Hospitals need to create separate areas for patients with known or suspected COVID19 and for those who are unlikely to have the disease [29]. In addition, strict monitoring for nosocomial acute respiratory illness is essential, especially in non-COVID-19 areas.

The IPC team has a crucial role in all hospitals since it is responsible for drawing up protocols on PPE use and hand hygiene monitoring, providing IPC training for all staff, and ensuring adequate implementation of measures taken. The importance of regularly cleaning and disinfecting all surfaces and medical equipment between patient contacts to reduce fomite transmission and of ensuring proper ventilation should be stressed to all staff. Finally, because asymptomatic infected patients can transmit the virus, consideration should be given to routine weekly PCR testing of all frontline staff, and possibly even patients in non-COVID wards, regardless of whether or not there is an outbreak [25]. Daily surveillance rounds to monitor compliance with preventive measures are also recommended.

The COVID-19 pandemic constitutes an unprecedented challenge for healthcare systems and communities worldwide. We hope that the lessons learned from this nosocomial outbreak at our hospital with a negative PCR for COVID-19 patients will help strengthen measures to protect against such outbreaks and significantly reduce the risk of in-hospital transmission. We have described how our hospital implemented infection control measures on a COVID-19-free ward at the peak of the pandemic, and how the entire hospital was forced to implement major changes in a short time. Hospitals should implement contingency plans that include IPC protocols for COVID-19-free areas.

Author Contributions: Conceptualization: M.M.M., C.H.L., R.G.-F., and J.P.H. Methodology: M.M.M., C.H.L., I.L.M., L.S., C.B.G., M.H., and M.C. Validation: M.D.A.J., M.M.M., J.P., C.G.J., J.V.-G., Formal analysis: M.M.M., C.H.L., C.G.J., Investigation: L.S., J.V.-G., C.B.G., M.H., Resources: C.G.J., M.C., J.P., J.P.H. Writing original draft preparation: M.M.M., C.H.L., J.P. and J.P.H., Writing review and editing M.M.M. and C.H.L., Visualization: C.H.L., I.L.M., Supervision: M.M.M., J.P. and J.P.H. All authors have read and agreed to the published version of the manuscript.

Funding: This research received no external funding.

Institutional Review Board Statement: The authors declare that they have all read the current "Instructions to Authors" and comply with those. The study was approved by the Clinical Research Ethical Committee (CEIC) of Parc de Salut Mar (register $n^{\circ}$ 2020/9508).

Informed Consent Statement: The need for written informed consent was waived by the Clinical Research Ethical Committee (CEIC) of Parc de Salut Mar due to the observational nature of the study and retrospective analysis. The authors confirm that all methods were carried out in accordance with relevant guidelines and regulations.

Data Availability Statement: The authors confirm that the data supporting the findings of this study are available within the article. Demographic, clinical, laboratory, and epidemiological data were collected from hospital and primary care electronic medical records.

Acknowledgments: We are indebted to the many front-line physicians and nurses caring for patients during the COVID-19 pandemic in our country.

Conflicts of Interest: The authors declare no conflict of interest. 


\section{References}

1. Guan, W.-J.; Ni, Z.-Y.; Hu, Y.; Liang, W.-H.; Chun-Quan China Medical Treatment Expert Group for Covid-19; He, J.-X.; Liu, L.; Shan, H.; Lei, C.-L.; Hui, D.S.; et al. Clinical Characteristics of Coronavirus Disease 2019 in China. N. Engl. J. Med. 2020, 382, 1708-1720. [CrossRef] [PubMed]

2. COVID-19 Situation Update Worldwide, as of 29 April 2021, (n.d.). Available online: https://www.ecdc.europa.eu/en/ geographical-distribution-2019-ncov-cases (accessed on 29 April 2021).

3. Coronavirus SARS-CoV-2. Canal Salut, (n.d.). Available online: https://canalsalut.gencat.cat/ca/salut-a-z/c/coronavirus-2019 -ncov / (accessed on 1 May 2021).

4. $\quad$ Black, J.R.M.; Bailey, C.; Przewrocka, J.; Dijkstra, K.K.; Swanton, C. COVID-19: The case for health-care worker screening to prevent hospital transmission. Lancet 2020, 395, 1418-1420. [CrossRef]

5. Islam, M.S.; Rahman, K.M.; Sun, Y.; Qureshi, M.O.; Abdi, I.; Chughtai, A.A.; Seale, H. Current knowledge of COVID-19 and infection prevention and control strategies in healthcare settings: A global analysis. Infect. Control. Hosp. Epidemiol. 2020, 41, 1196-1206. [CrossRef] [PubMed]

6. Wang, D.; Hu, B.; Hu, C.; Zhu, F.; Liu, X.; Zhang, J.; Wang, B.; Xiang, H.; Cheng, Z.; Xiong, Y.; et al. Clinical Characteristics of 138 Hospitalized Patients With 2019 Novel Coronavirus-Infected Pneumonia in Wuhan, China. JAMA 2020, 323, 1061. [CrossRef] [PubMed]

7. Aghaizu, A.; Elam, G.; Ncube, F.; Thomson, G.; Szilágyi, E.; Eckmanns, T.; Poulakou, G.; Catchpole, M. Preventing the next 'SARS' -European healthcare workers' attitudes towards monitoring their health for the surveillance of newly emerging infections: Qualitative study. BMC Public Health 2011, 11, 541. [CrossRef]

8. Li, Y.-K.; Peng, S.; Li, L.-Q.; Wang, Q.; Ping, W.; Zhang, N.; Fu, X.-N. Clinical and Transmission Characteristics of Covid-19-A Retrospective Study of 25 Cases from a Single Thoracic Surgery Department. Curr. Med Sci. 2020, 40, 295-300. [CrossRef]

9. Burrer, S.L.; De Perio, M.A.; Hughes, M.M.; Kuhar, D.T.; Luckhaupt, S.E.; McDaniel, C.J.; Porter, R.M.; Silk, B.; Stuckey, M.J.; Walters, M. Characteristics of Health Care Personnel with COVID-19 - United States, February 12-April 9, 2020. MMWR. Morb. Mortal. Wkly. Rep. 2020, 69, 477-481. [CrossRef]

10. Morawska, L.; Milton, D.K. It Is Time to Address Airborne Transmission of Coronavirus Disease 2019 (COVID-19). Clin. Infect. Dis. 2020, 2311-2314. [CrossRef]

11. Jayaweera, M.; Perera, H.; Gunawardana, B.; Manatunge, J. Transmission of COVID-19 virus by droplets and aerosols: A critical review on the unresolved dichotomy. Environ. Res. 2020, 188, 109819. [CrossRef]

12. Greenhalgh, T.; Jimenez, J.L.; A Prather, K.; Tufekci, Z.; Fisman, D.; Schooley, R. Ten scientific reasons in support of airborne transmission of SARS-CoV-2. Lancet 2021, 397, 1603-1605. [CrossRef]

13. Ye, G.; Lin, H.; Chen, S.; Wang, S.; Zeng, Z.; Wang, W.; Zhang, S.; Rebmann, T.; Li, Y.; Pan, Z.; et al. Environmental contamination of SARS-CoV-2 in healthcare premises. J. Infect. 2020, 81, e1-e5. [CrossRef]

14. Arons, M.M.; Hatfield, K.M.; Reddy, S.C.; Kimball, A.; James, A.; Jacobs, J.R.; Taylor, J.; Spicer, K.; Bardossy, A.C.; Oakley, L.P.; et al. Presymptomatic SARS-CoV-2 Infections and Transmission in a Skilled Nursing Facility. N. Engl. J. Med. 2020, 382, $2081-2090$. [CrossRef] [PubMed]

15. Ong, S.W.X.; Tan, Y.K.; Chia, P.Y.; Lee, T.H.; Ng, O.T.; Wong, M.S.Y.; Marimuthu, K. Air, Surface Environmental, and Personal Protective Equipment Contamination by Severe Acute Respiratory Syndrome Coronavirus 2 (SARS-CoV-2) From a Symptomatic Patient. JAMA 2020, 323, 1610. [CrossRef] [PubMed]

16. Wee, L.E.; Sim, X.Y.J.; Conceicao, E.P.; Aung, M.K.; Goh, J.Q.; Yeo, D.W.T.; Gan, W.H.; Chua, Y.Y.; Wijaya, L.; Tan, T.T.; et al. Containment of COVID-19 cases among healthcare workers: The role of surveillance, early detection, and outbreak management. Infect. Control. Hosp. Epidemiol. 2020, 41, 765-771. [CrossRef] [PubMed]

17. Infectious Diseases Society of America Guidelines on Infection Prevention in Patients with Suspected or Known COVID-19, (n.d.). Available online: https:/ /www.idsociety.org/practice-guideline/covid-19-guideline-infection-prevention/ (accessed on 19 May 2020).

18. Wang, Y.; Wang, Y.; Chen, Y.; Qin, Q. Unique epidemiological and clinical features of the emerging 2019 novel coronavirus pneumonia (COVID-19) implicate special control measures. J. Med. Virol. 2020, 92, 568-576. [CrossRef]

19. Crespo, M.; Pérez-Sáez, M.J.; Redondo-Pachón, D.; Llinàs-Mallol, L.; Montero, M.M.; Villar-García, J.; Arias-Cabrales, C.; Buxeda, A.; Burballa, C.; Vázquez, S.; et al. COVID-19 in elderly kidney transplant recipients. Arab. Archaeol. Epigr. 2020, 20. [CrossRef] [PubMed]

20. Arenas, M.D.; Crespo, M.; Pérez-Sáez, M.J.; Collado, S.; Redondo-Pachón, D.; Llinàs-Mallol, L.; Montero, M.M.; Villar-García, J.; Arias-Cabrales, C.; Barbosa, F.; et al. Clinical Profiles in Renal Patients with COVID-19. J. Clin. Med. 2020, 9, 2665. [CrossRef]

21. Stone, S.P.; Cooper, B.S.; Kibbler, C.C.; Cookson, B.D.; A Roberts, J.; Medley, G.F.; Duckworth, G.; Lai, R.; Ebrahim, S.; Brown, E.M.; et al. The ORION statement: Guidelines for transparent reporting of outbreak reports and intervention studies of nosocomial infection. Lancet Infect. Dis. 2007, 7, 282-288. [CrossRef]

22. Charlson, M.E.; Charlson, R.E.; Peterson, J.C.; Marinopoulos, S.S.; Briggs, W.M.; Hollenberg, J.P. The Charlson comorbidity index is adapted to predict costs of chronic disease in primary care patients. J. Clin. Epidemiol. 2008, 61, 1234-1240. [CrossRef]

23. Kawana, A.; Teruya, K.; Kirikae, T.; Sekiguchi, J.-I.; Kato, Y.; Kuroda, E.; Horii, K.; Saito, S.-I.; Ohara, H.; Kuratsuji, T.; et al. "Syndromic surveillance within a hospital" for the early detection of a nosocomial outbreak of acute respiratory infection. Jpn. J. Infect. Dis. 2006, 59, 377. 
24. Infection Prevention and Control and Preparedness for COVID-19 in Healthcare Settings-Third Update, (n.d.). Available online: https://www.ecdc.europa.eu/en/publications-data/infection-prevention-and-control-and-preparedness-covid-19 -healthcare-settings (accessed on 19 May 2020).

25. A Treibel, T.; Manisty, C.; Burton, M.; McKnight, Á.; Lambourne, J.; Augusto, J.B.; Couto-Parada, X.; Cutino-Moguel, T.; Noursadeghi, M.; Moon, J.C. COVID-19: PCR screening of asymptomatic health-care workers at London hospital. Lancet 2020, 395, 1608-1610. [CrossRef]

26. Rickman, H.M.; Rampling, T.; Shaw, K.; Martinez-Garcia, G.; Hail, L.; Coen, P.; Shahmanesh, M.; Shin, G.Y.; Nastouli, E.; Houlihan, C.F. Nosocomial Transmission of Coronavirus Disease 2019: A Retrospective Study of 66 Hospital-acquired Cases in a London Teaching Hospital. Clin. Infect. Dis. 2021, 72, 690-693. [CrossRef] [PubMed]

27. Carter, B.; Collins, J.; Barlow-Pay, F.; Rickard, F.; Bruce, E.; Verduri, A.; Quinn, T.; Mitchell, E.; Price, A.; Vilches-Moraga, A.; et al Nosocomial COVID-19 infection: Examining the risk of mortality. The COPE-Nosocomial Study (COVID in Older PEople). J. Hosp. Infect. 2020, 106, 376-384. [CrossRef]

28. Jewkes, S.V.; Zhang, Y.; Nicholl, D.J. Nosocomial spread of COVID-19: Lessons learned from an audit on a stroke/neurology ward in a UK district general hospital. Clin. Med. 2020, 20, e173-e177. [CrossRef] [PubMed]

29. Van Praet, J.T.; Claeys, B.; Coene, A.-S.; Floré, K.; Reynders, M. Prevention of nosocomial COVID-19: Another challenge of the pandemic. Infect. Control. Hosp. Epidemiol. 2020, 41, 1355-1356. [CrossRef] [PubMed] 